\title{
TBI.01. Traumatic Brain Injury in Pediatric and Adolescent Populations
}

\author{
BRAGA, L.W. ${ }^{1}$
}

${ }^{1}$ Sarah Kubistchek Hospital Network

Introduction: Ecological neurehabilitation should consider three integrated components that comprise an individual: the biological (brain); cultural (environment/context); and the individual (self). Since acquired brain injury $(A B I)$ is a life-long process, it requires an ecological neurorehabilitation program that is sustainable throughout the patient's development and can be incorporated into daily routines, as well as adapted to the skills and interests inherent to each stage of life. During childhood, the most natural setting is the family/home; in adolescence, it is more based on peer interaction. The ecological process of neurorehabililitation occurs by enriching the environment (the patient's context) in a more natural manner. The aim is to promote positive changes in the neuronal networks (the biological) and in the quality of life of each child (the individual self). Objectives: To demonstrate, through two evidence-based studies, how ecological neurorehabilitation promotes better results: in children with $\mathrm{ABI}$, through a family-centered methodology; and in adolescence, through peer-based intervention. Methods: In the first study, we randomized 2 groups of children with $\mathrm{ABI}$ to compare the results of 2 different types of treatment approaches after 1 year: a group of 38 children treated within an ecological, family-centered methodology and another group, with 34 children, treated exclusively by professionals. The children were assessed before and one year after starting treatment, using the WISC Scale and the SARAH Scale for Motor and Functional Development. In the second study, preadolescent and adolescents were randomly assigned to 2 intervention groups: 14 preand adolescents treated within an ecological, peer-based intervention program using metacognition, and another group with 15 pre- and adolescents treated with the familybased methodology, a model more appropriate for children. The 2 groups were evaluated using the Self Concept and Learning Strategies Scales, before and three months after the programs start. Results: In the first study, the results showed that the children treated at home, with the participation of family, had better cognitive $(p<0.05)$ and motor $(p<0.05)$ results than those treated exclusively by professionals. The second study showed that the preadolescents treated with a peer-based metacognitive approach had better results on the Self-concept $(p<0.05)$ and Learning Strategies $(p<0.05)$ Scales than those treated with the family-centered methodology. Conclusions: Ecological neurorehabilitation based on the patient's setting and on each developmental stage of the child and adolescent with $A B I$ presents better results than more conventional approaches. This is due to the fact that the rehabilitation within the ecological framework is based on the individual's interests and performed as part of daily life routine, making it more pleasurable and easier to perform more frequently. An effective rehabilitation ecological program adapts to the changing needs of each individual, and maximizes potential at each stage of life.

BRAGA, L.W. 2013. Traumatic Brain Injury in Pediatric and Adolescent Populations, p.7. In: Oriá, Reinaldo Barreto; Andrade, Geanne Matos de; Bruin, Veralice Meireles S. de. I International Symposium in Neuroscience Meeting [Blucher Neuroscience Proceedings $\mathrm{n} .1$ v.1]. São Paulo: Blucher, 2014, http://dx.doi.org/10.5151/isnm-sine3 